\title{
Erratum to: Injectability Evaluation: an Open Issue
}

\author{
Francesco Cilurzo, ${ }^{1,3}$ Francesca Selmin, ${ }^{1}$ Paola Minghetti, ${ }^{1}$ Marco Adami, ${ }^{2}$ Elisa Bertoni, ${ }^{2}$ \\ Sara Lauria, ${ }^{2}$ and Luisa Montanari ${ }^{1}$
}

\section{Erratum to: AAPS PharmSciTech \\ DOI: 10.1208/s12249-011-9625-y}

On page 605 under the "Materials" header, the authors inadvertently noted the glass syringe size as $0.6 \mathrm{~mm}$ instead of $6.0 \mathrm{~mm}$ : "A Luer Lock glass syringe (BD Hypak, USA), 6.0 $\mathrm{mm}$ inner diameter, was filled with $1 \mathrm{~mL}$ tested formulation."

Throughout the paper, megapascal units were inadvertently depicted as " $\mathrm{mPa}$ " instead of " $\mathrm{MPa}$ " during production. All instances of "mPa" should instead be "MPa."

The online version of the original article can be found at http:// dx.doi.org/10.1208/s12249-011-9625-y.

\footnotetext{
${ }^{1}$ Department of Pharmaceutical Sciences "Pietro Pratesi", Università degli Studi di Milano, via G. Colombo, 71, 20133, Milan, Italy.

${ }^{2}$ Industrial Development Department, Italfarmaco S.p.A., 20126, Milan, Italy.

${ }^{3}$ To whom correspondence should be addressed. (e-mail: francesco.cilurzo@unimi.it; )
} 